ISSN: 2238-8052

\title{
MICHEL FOUCAULT E O DISCURSO: AS IMPLICAÇÕES TEÓRICO- METODOLÓGICAS DA ANÁLISE DO DISCURSO A PARTIR DAS PERSPECTIVAS DA ARQUEOLOGIA DO SABER E DA GENEALOGIA DO PODER
}

\author{
MICHEL FOUCAULT AND THE DISCURSE: THE THEORETICAL-METHODOLICAL \\ PERSPECTIVES OF THE DISCURSE ANALYSIS FROM ARCHAEOLOGY OF \\ KNOWLIDGE AND GENEALOGY OF POWER
}

Hugo Arruda de MORAIS ${ }^{1}$

Palavras-chave: Michel Foucault Discurso Arqueologia Genealogia

Keywords: Michel Foucault Discourse Archaeology Genealogy

\section{R E S U M O}

Este escrito possui como objetivo principal fazer reflexões acerca do Discurso na obra de Michel Foucault, respeitando os vários posicionamentos que ele tomou ao longo de sua trajetória intelectual. Claramente, pode-se distinguir duas grandes fases do pensamento foucaultiano: a primeira, composta pelos História da Loucura, 0 nascimento da Clínica e, principalmente, A Arqueologia do Saber; obras que compõem os estudos do que se denominou de Projeto Arqueológico; uma outra fase, diz respeito aos estudos do Projeto Genealógico, que contaram com a publicação de Vigiar e Punir e da História da Sexualidade I: A Vontade de Saber, além de uma série de conferências, palestras e aulas através das quais Foucault trouxe suas concepções da gênese do saber, a partir do entendimento do poder. A metodologia do escrito fundamentou-se, notadamente, nos procedimentos de pesquisa relativos à revisão bibliográfica, a partir da seleção das principais obras de Foucault, e interpretação livre do conteúdo destas. 0 resultado principal replicou-se na constatação de que existem implicações teórico-metodológicas do estudo do discurso a partir das abordagens da Arqueologia e da Genealogia, mas que essas implicações não significam fragmentação da obra e nem do pensamento de Michel Foucault.

\begin{abstract}
A B S T R A C T
The main objective of this paper is to reflect on the Discourse in the Michel Foucault's work, respecting the various positions that he has taken throughout his intellectual trajectory. Clearly, it is possible to distinguish two major phases of Foucault's thought: the first one, known as Archaeological Project is composed by the History of Madness, The Birth of the Clinic and, mainly, The Archaeology of Knowledge; the other phase concerns the studies of the Genealogical Project, which included studies as Discipline and Punish, History of Sexuality I: The Will to Know and a series of lectures which Foucault brought his conceptions of the genesis of knowledge, from his understanding of power. This study is based on the Foucault's main literature review and its free interpretation. The main result is the understanding that there are different theoreticalmethodological discourse approaches between the Archaeology of Knowledge and the Genealogy of power, but such differences do not mean fragmentation in Michel Foucault's thoughts or work. trouver des solutions qui conviennent à tous.
\end{abstract}

\footnotetext{
1 Doutor em Geografia pelo Programa de Pós-graduação em Geografia da Universidade Federal de Pernambuco (PPGEOUFPE). E-mail: hugo.geografia@yahoo.com.br.
} 


\section{CONSIDERAÇÕES INICIAIS}

Em entrevista informal com estudantes de Los Angeles, em 1975, intitulada Diálogo e Poder, e transcrita no Livro Michel Foucault: Estratégia, Poder-Saber, Foucault (2006) ao ser questionado por um estudante se ele era um filósofo ou um historiador, assim respondeu: "Nem um nem outro". Esta resposta foi acompanhada de outra com relação à sua preocupação de estudioso:

Eu me dei como objeto uma análise do discurso, fora de qualquer ponto de vista. Meu programa se fundamenta tampouco nos métodos da linguística. A noção de estrutura não tem nenhum sentido para mim. 0 que me interessa, no problema do discurso, é o fato de que alguém disse alguma coisa em um dado momento (FOUCAULT, 2006, p. 255).

Como o próprio autor afirmou em suas respostas aos estudantes, ele se interessava era pelo discurso, um discurso enquanto um acontecimento num dado momento. A análise do discurso permeia a obra de Foucault, porém respeitando os vários posicionamentos que ele tomava na medida em que a construía. Daí por que a sua obra é extremamente vasta e muito complexa, tanto quanto ele próprio o era

Segundo argumenta Rabinow; Dreyfus (2010), Foucault é um autor que supera ou vai além de pelo menos três posições: o estruturalismo, a fenomenologia e a hermenêutica. Na obra foucaultiana, pode-se distinguir pelo menos duas grandes fases ou dois grandes projetos ao longo de sua formação enquanto estudioso. Os trabalhos compostos pelos livros História da Loucura, 0 nascimento da Clínica e, principalmente, A Arqueologia do Saber compõem os seus estudos iniciais que se denominou de Projeto Arqueológico. No que diz respeito aos estudos do Projeto Genealógico, estes surgem a partir da década de 1970, principalmente com a publicação de Vigiar e Punir e da História da Sexualidade I: A Vontade de Saber, além de uma série de conferências, palestras e aulas através das quais Foucault trouxe suas concepções da gênese do saber, a partir do entendimento do poder.

Do ponto de vista do método da construção do escrito ora apresentado, utilizamo-nos da hermenêutica como recurso teórico-metodológico, uma vez que possibilita a interpretação de textos que tratam do tema, permitindo com isso compreender o conteúdo central do pensamento de Michel Foucault.

Com isso, o objetivo do presente texto reside na reflexão com relação ao discurso ou à análise do discurso, dentro da visão de Michael Foucault (Figura 1), ou de suas várias fases. Procurou-se fazer uma revisão e seleção de suas principais ideias acerca do discurso no âmbito do processo de construção social, deixando claro que o presente ensaio faz parte de reflexões sobre o pensamento foucaultiano e que não necessariamente esgota o conteúdo desse debate, mas busca responder ao seguinte questionamento: Quais as implicações teórico-metodológicas do estudo do discurso a partir das abordagens da Arqueologia e da Genealogia em Foucault? 
Figura 1: Michel Foucault

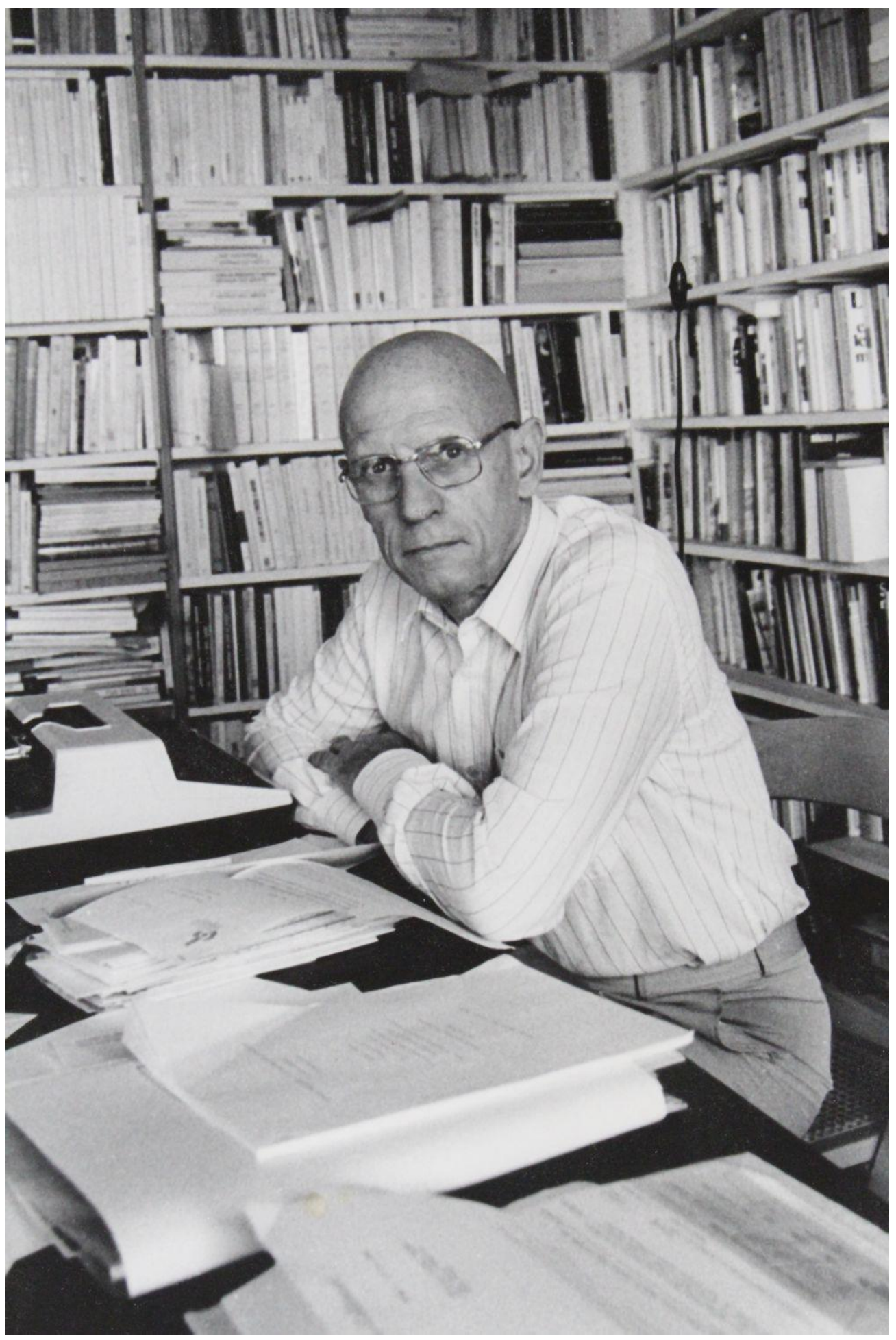

Fonte: https://www.edition-originale.com/media/h-3000-foucault_michel_michel-foucault-portrait11_1984_edition-originale_autographe_2_53965.jpg.

Para tal, a estrutura do texto foi elaborada de maneira a: primeiramente, colocar a ideia geral do texto, a partir da reflexão com relação ao pensamento arqueológico de Foucault e como o discurso 
se encontra nessa sua fase; em seguida, apresentaremos uma discussão em torno da noção de discurso tomando por base o pensamento genealógico de Foucault; e, por último, tecemos a fim de conclusão do trabalho comentários com relação as implicações teórico-metodológicas do estudo do discurso a partir das abordagens da Arqueologia e da Genealogia em Foucault.

\section{MICHEL FOUCAULT E O DISCURSO EM A ARQUEOLOGIA DO SABER ${ }^{2}$}

No que tange à ideia e conceituação da Análise de Discurso (AD), pode-se apontar que esses estudos começaram com Foucault (2012), através da sua A Arqueologia do Saber, com a qual apresenta o discurso como um acontecimento que deve ser estudado dentro de uma perspectiva da "descontinuidade, de ruptura, de limiar, de limite, de série, de transformação" (FOUCAULT, 2012, p. 25). Em outras palavras, Foucault (2012), ao estudar o discurso, na perspectiva Arqueológica, estava preocupado em mostrar a problematização do discurso e de sua emergência no âmbito do campo da formação do conhecimento e das ciências humanas.

Com isso, o tema central em A Arqueologia do Saber, no âmbito da análise do discurso, em Foucault, refere-se à formulação da noção de enunciado e discurso. Ou mais especificamente, à constituição de determinados enunciados e discursos.

O questionamento central de Foucault (2012), ao estudar os enunciados, e de forma bem específica, os enunciados que compõem os discursos das ciências humanas arqueologicamente, numa tentativa de desenvolver uma Teoria Social do Discurso ${ }^{3}$, era saber por que determinados enunciados foram produzidos e qual o contexto em que tais enunciados apareciam. Ou seja, a preocupação de Foucault estava centrada na questão da emergência de determinados enunciados separados da situação local, da contingência.

O pensamento foucaultiano se justifica dentro dessa concepção, uma vez que Foucault (2012) tentava mostrar que os discursos não se justificam por si mesmo, mas sim, emergem dentro de um campo enunciativo no qual são construídos. Daí o debate central em A Arqueologia do Saber ser o conjunto de enunciados em seu acontecimento: “[...] essa teoria não pode ser elaborada sem que apareça, em sua pureza não sintética, o campo dos fatos do discurso a partir do qual são construídas" (FOUCAULT, 2012, p. 32).

Tendo em vista essa preocupação teórico-metodológica do autor, por enunciados entende-se como uma "unidade elementar do discurso" de indivíduos que, através de um conjunto de signos, expressa o jogo de relações de sua existência:

\footnotetext{
${ }^{2}$ As concepções aqui apresentadas com relação ao pensamento arqueológico de Foucault estão centradas nas reflexões feitas com base no livro A Arqueologia do Saber (2012).

3 Em A Arqueologia do Saber, Foucault (2012) tentou mostrar que os discursos das ciências humanas se apresentavam a partir de regras, dentro de um campo de discursivo, mas que ao mesmo tempo, eram descontínuos, ou seja, que não se apresentavam de forma contínua ao longo da história.
} 
Chamaremos enunciado a modalidade de existência própria desse conjunto de signos: modalidade que lhe permite ser algo diferente de uma série de traços, algo diferente de uma sucessão de marcas em uma substância, algo diferente de um objeto qualquer fabricado por um ser humano; modalidade que lhe permite estar em relação com um domínio de objetos, prescrever uma posição definida a qualquer jeito possível, estar situado entre outras performances verbais, estar dotado, enfim, de uma materialidade repetível (FOUCAULT, 2012, p. 130).

Essa perspectiva foucaultina apresenta o enunciado não como uma simples unidade gramatical, mas como uma ação do sujeito, não de forma individualizada, na busca da verdade. Segundo apresentava Foucault (2012), os enunciados aparecem na fala dos sujeitos como uma ação que surge a partir ou que tem condições de existência através de outros sistemas de enunciados. Sabese que o sujeito ao pronunciar determinados enunciados vai muito além de uma simples pronúncia de palavras. Descrever um enunciado na perspectiva foucaultiana é, portanto, buscar entender que os enunciados não são uma função restrita a frases e orações, uma vez que as mesmas frases podem ter sentidos diferentes. Mas, buscando entendê-los dentro de um conjunto de saberes, no qual a frase gramaticalmente só vai ter sentido a partir do discurso, ou seja, do conjunto de saberes, em forma de enunciados, transmitido pelo sujeito. Assim, dizia ele:

Se não houvesse enunciados, a língua não existiria; mas nenhum enunciado é indispensável à existência da língua. A língua só existe a título de sistema de construção para enunciados possíveis; mas, por outro lado, ela só existe a título de descrição obtida a partir de um conjunto de enunciados reais (FOUCAULT, 2012, p. 103).

Segundo essa posição, Foucault (2012) deixava claro que a língua é constituída por um sistema de enunciados, mas a questão não residiria no estudo da língua em si, enquanto signo ou como sistema relacional $^{4}$, mas como um campo de acontecimento dos discursos no seu conjunto finito de regras. Com isso, a questão para o arqueólogo seria saber em que regras os enunciados foram constituídos permitindo a construção e a produção de novos enunciados. Isso porque, segundo nos mostra Foucault (2012), todo o enunciado está inserido dentro de um contexto, o qual só tem existência na sua relação com outros enunciados, ou seja, dentro de um campo específico de relações: “[...] certos atos ilocutórios só podem ser considerados como acabados em sua unidade singular se vários enunciados tiverem sido articulados, cada um no lugar que lhe convém. Esses atos são, pois, constituídos por uma série ou soma desses enunciados [...]" (FOUCAULT, 2012, p. 101).

Essa perspectiva se levanta uma vez que o sujeito no uso de sua língua pode pronunciar e trazer a público uma série de enunciados. Porém, os acontecimentos para a existência ou as regras

\footnotetext{
${ }^{4}$ Essa concepção da língua como um sistema relacional pode ser vista na Filosofia da Linguagem de Wittgenstein, uma vez que seu pensamento em Tractatus Logico-Philosophicus está centrado no debate de como a linguagem permite a compreensão da realidade. Ou seja, se a filosofia busca entender a realidade, ele pode conseguir através da linguagem. Em Tratactus repousa no conceito de "Signos" (nome), onde para Wittgenstein, todo signo representa um objeto, e na combinação signo e objeto é possível configurar a realidade. Para esse entendimento é necessário saber ou compreender o que constitui a proposição e as proposições elementares para a compreensão da linguagem. Para Wittgenstein, existe uma relação entre pensamento e linguagem, como também, entre a realidade. Sua teoria se baseia na ideia de que a realidade é afigurada pela linguagem. Ou seja, na linguagem há elementos que possibilitam ou permitem a construção dessa relação.
} 
para as enunciações se dão de forma bem limitada. Os enunciados, enquanto constituintes dos discursos, ou como suas unidades, se caracterizam através de signos, mas principalmente, pelas regras que mantêm o controle sobre os indivíduos que os enunciam.

Para Foucault (2012), a análise do campo discursivo trata-se de compreender o enunciado na sua situação de acontecimento, ou seja, na sua "singular existência". Estabelece-se em A Arqueologia do saber, e Foucault (2012) deixa bem claro, que o enunciado é sempre o acontecimento em que seu sentido não se esgota inteiramente, ele está sempre aberto a repetições e transmissões, ou seja, a regularidades. Segundo o autor, todo enunciado é fruto de outros enunciados que o precedem e o seguem, ou seja, de um jogo de relações.

Delineando essa condição, Foucault (2012) reafirmou que o enunciado de um sujeito, como uma intenção de realizar um objetivo comunicativo, se dá através de um discurso, porém os enunciados proferidos não necessariamente precisam ter uma ordem gramatical lógica, uma vez que a sua preocupação estava centrada nos enunciados no seu jogo de relações, com suas relações de coexistência, de funcionamento e de corelação ${ }^{5}$.

Para pensar os enunciados como sérios, Foucault (2012) buscava a regularidade de certos atos de fala sérios junto a outros enunciados do mesmo tipo. Em A Arqueologia, o estudo dos enunciados estava centrado em analisar as inter-relações dos enunciados sérios e não sérios dentro do sistema de regras que o fazem emergirem, ou seja, dentro de um "campo enunciativo"6.

Daí sem dúvida pode-se afirmar que essa deve ser a preocupação do arqueólogo e era a centralidade do pensamento foucaultiano em A Arqueologia do Saber, buscar as regras de formação dos enunciados, num entendimento de que essas regras são os modos como os enunciados se relacionam e permitem a regularidade de certos enunciados que se tornam sérios. Ou seja, o que faz com que certas pessoas considerem certos enunciados como verdadeiros? Pode-se perguntar também: O que torna o enunciado sério é a sua relação com o outro enunciado?

A preocupação de Foucault (2012) era mostrar quem tem o poder de falar, de proferir determinados discursos e esses serem considerados como verdades ou um saber verdadeiro. Com isso, todo enunciado traz em si a questão do saber ou a vontade do saber do sujeito que o fala. 0 discurso

\footnotetext{
${ }^{5}$ Dentro dessa perspectiva, Foucault estava centrando suas análises nos enunciados sérios (Rabinow, Dreyfus, 2010). Segundo nos mostra esse autor, os enunciados sérios são aqueles enunciados separados da situação local, da "contingência", ou seja, dos enunciados cotidianos. A preocupação do arqueólogo era com os enunciados institucionalizados, que buscam uma repetição e sua transmissão (regularidade), que se apresentam como verdadeiros perante os enunciados do cotidiano. Assim, confirma Rabinow; Dreyfus (2010): "Segundo Foucault, trata-se de uma manifestação de uma vontade, que não cessa de se reforçar, de se tornar mais profunda e mais incontornável. 0 método da justificação e refutação confere a esses atos de fala sérios sua pretensão ao saber e faz deles objetos a serem estudados, repetidos e transmitidos" (RABINOW; DREYFUS, 2010, p. 63)

${ }^{6}$ Rabinow; Dreyfus (2010) mostra que é dentro desse campo de relações e de jogo de regras que se estabelecem os enunciados ou o "sistema de enunciados": "[...] o arqueólogo limita-se a encontrar as regras locais de transformação que, em um dado período, em uma formação discursiva, particular, definem o que deve ser considerado como enunciado [...] se uma regra é um princípio formal que define as condições necessárias e suficientes às quais um ato discursivo deve satisfazer antes de poder ser considerado sério, não há regras absolutamente. Ou melhor, as regras que regem o sistema de enunciado não são nada mais do que os modos pelos quais os enunciados realmente se relacionam" (RABINOW; DREYFUS, 2010, p. 71).
} 
não é simplesmente uma manifestação da fala ou do ato de fala de um sujeito, mas um conjunto de enunciados que se torna um objeto de seu desejo e verdade para o sujeito dentro de um conjunto de outros enunciados 7 .

Dessa forma, o discurso, na perspectiva foucaultiana em A Arqueologia do Saber, é um domínio de enunciados, uma forma prática de dominar enunciados. Os discursos são mais que um conjunto de signos proferidos por sujeitos, mais que a língua e atos de fala. 0 discurso é uma prática social que é constituída por um jogo de regras ou relações sociais de caráter discursivo e não discursivo. Daí todo enunciado, enquanto elemento do discurso, é mais do que uma simples frase, ele é e está dentro de um campo de relações de vários outros enunciados e dentro de um controle de regras ou de um jogo de regras que o determinam ${ }^{8}$.

Como se percebe, as análises do Foucault (2012), enquanto arqueólogo, parte dessa noção de que todo o enunciado está submetido a um conjunto de regras e que a análise do discurso é uma análise do campo de acontecimento do discurso, ou seja, da busca de compreensão do enunciado na sua situação de acontecimento, de singularidade. Na análise arqueológica de Foucault, o arqueólogo tem que ter em mente que os enunciados se apresentam como um acúmulo de conhecimento que aparece de forma descontínua no tempo e no espaço.

A análise do campo discursivo é orientada de forma inteiramente diferente; trata-se de compreender o enunciado na estreiteza e singularidade de sua situação; de determinar as condições de sua existência, de fixar seus limites de forma mais justa, de estabelecer suas correlações com os outros enunciados a que pode estar ligado, de mostrar que outras formas de enunciação excluem. [...] deve-se mostrar por que não poderia ser outro, como ocupa, no meio dos outros e relacionado a eles, um lugar que nenhum outro poderia ocupar. [...] Na verdade, a supressão sistemática das unidades inteiramente aceitas permite, inicialmente, restituir ao enunciado sua singularidade de acontecimento e mostrar que a descontinuidade não é somente um desses grandes acidentes que produzem uma falha geológica da história, mas já no simples fato do enunciado (FOUCAULT, 2012, p. 34).

É dessa concepção que se sabe que os enunciados são acontecimentos descontínuos, ou seja, não apresentam uma linearidade no seu acontecimento histórico. 0 enunciado é um acontecimento único, mas este é passível de repetição, transformação e dispersão9.

\footnotetext{
7 Para Foucault (2012), os lugares onde aparecem os discursos também são importantes, pois esses lugares podem dar legitimidade ao discurso, como também, a posição do sujeito nos vários discursos: Qual a posição do sujeito dentro do campo enunciativo? Quem fala um enunciado sério? O enunciado é um saber do sujeito que fala e se apresenta em forma de discurso, ao mesmo tempo, em que tem conteúdos concretos, e se encontra num determinado tempo e espaço. Porém, ele só se torna um enunciado sério dependendo do sujeito e do lugar dele dentro do campo discursivo.

${ }^{8}$ Segundo o próprio Foucault (2011), em A ordem do discurso, todo discurso é esse domínio de enunciados, mas um domínio que se constitui como uma prática formada por regras, não necessariamente lógicas, mas por regras que se dão de forma específica em cada contexto social, histórico e espacial. Isso faz com que um enunciado seja um conjunto de ideias no qual o sujeito se encontra dando sentido às suas relações cotidianas e a determinadas situações sociais vivenciadas.

${ }^{9}$ O princípio da descontinuidade está presente no método foucaultiano em A Arqueologia do Saber, mas também, em A Ordem do Discurso (2011), onde o autor apresenta a ideia de não haver um discurso único ou original. Para ele, os discursos e, consequentemente, os enunciados, devem ser tratados ou entendidos como práticas ou acontecimentos descontínuos: "Um Princípio de descontinuidade: o fato de haver sistemas de rarefação não quer dizer que por baixo deles e para além deles reine um grande discurso ilimitado, contínuo e silencioso que fosse por eles reprimido e recalcado e que nós tivéssemos por missão
} 
Diante dessa perspectiva, todo o enunciado é fruto de outros que o precedem e o seguem, através de descontinuidades, mas que mesmo dispersos, cada conjunto de enunciados constitui um conjunto de objetos ${ }^{10}$. Para Foucault (2012), o processo de enunciação do discurso tem como consequência uma série de relações que dão sentido a certos objetos. Não há discurso sem a formação de objeto, como também não há objetos sem uma relação direta com o discurso. Com isso, os objetos, na perspectiva foucaultiana, são as formas de conhecimento ou as formas de experiências situadas dentro do discurso. Os discursos são formados e constituídos por objetos, e esses sustentam os discursos, já que um conjunto de enunciados se relaciona a um conhecimento.

Nessa perspectiva arqueológica, uma das principais ideias de Foucault consistiu em apresentar os objetos como as formas de conhecimento das disciplinas das ciências humanas, daí a noção ou o conceito de formação discursiva ${ }^{11}$. Para Foucault, todo enunciado é determinado ou pertence a uma formação discursiva, não existe enunciado sem formação discursiva, pois a sua regularidade depende desta formação: “[...] a regularidade dos enunciados é definida pela própria formação discursiva. A lei dos enunciados e o fato de pertencerem à formação discursiva é a mesma coisa" (FOUCAULT, 2012, p. 143).

O que parece evidente nas investigações de Foucault é que os objetos de conhecimento são entidades que as disciplinas particulares ou as ciências reconhecem dentro de seus campos de interesse e que elas tomam como alvos de investigação. Ou seja, o objeto é constituído discursivamente e, dessa mesma maneira, se apresenta como uma regularidade ao longo do tempo, mesmo passando por modificações.

Com efeito, embora já mencionado, o discurso é fruto de uma soma de diversos conhecimentos que são colocados, a partir de um campo discursivo, e que se transformam e se estabelecem numa regularidade ao longo do tempo, mesmo que esses discursos apresentem-se de caráter descontínuo.

descobrir restituindo-lhe, enfim, a palavra. Não se deve imaginar, percorrendo o mundo e entrelaçando-se em todas as suas formas e acontecimentos, um não-dito ou um impensado que se deveria, enfim, articular ou pensar. Os discursos devem ser tratados como práticas descontínuas, que se cruzam por vezes, mas também se ignoram ou se excluem" (FOUCAULT, 2011, p.52).

10 Com relação à Formação dos objetos, no Método Foucaultiano, entende-se a ligação entre o conhecimento adquirido, entre discurso e prática, afirma Rabinow; Dreyfus (2010) ao citar Foucault: “[...] a tarefa que consiste não - não mais - em tratar os discursos como um conjunto de signos, mas como práticas que formam sistematicamente os objetos sobre os quais falam" (FOUCAULT apud RABINOW; DREYFUS, 2010, p. 82). Em A Arqueologia do saber, Foucault (2012) apontou que os objetos sociais são frutos dos discursos e de suas formações discursivas: "As relações discursivas [...] não são internas ao discurso: não ligam entre se os conceitos ou as palavras; não estabelecem entre as frases ou proposições uma arquitetura dedutiva ou retórica. Mas não são, entretanto, relações exteriores ao discurso, o que limitariam ou lhe imporiam certas formas, ou o forçariam, em certas circunstâncias, e enunciar certas coisas. Elas estão, de alguma maneira, no limite do discurso: oferecemlhe objetos de que pode falar, ou antes determinam o feixe de relações que o discurso deve efetuar para poder falar tais ou tais objetos, para poder abordá-los, nomeá-los, analisá-los, classificá-los, explicá-los etc. Essas relações caracterizam não a língua que o discurso utiliza, não as circunstâncias e que ele se desenvolve, mas o próprio discurso enquanto prática" (FOUCAULT, 2012, p. 56).

11 Por formação discursiva entende-se, a partir de Foucault (2012), um conjunto de enunciados que formam um conhecimento. Ou seja, a multiplicidade de conhecimentos sobre um determinado tema vai possibilitar a formação de um discurso. Para Foucault (2012), o discurso sobre a loucura é fruto não da existência do objeto loucura, mas da constituição e repetição de um conjunto de enunciados sobre a loucura. Daí a questão da formação discursiva não é o enunciado em si, mas a repetição ou a regularidade de enunciados que constitui o discurso sobre a loucura. 
Nossa suspeita é que Foucault (2012) mostrou que é o conjunto de condições históricas nas quais o sujeito está inserido que permite a emergência de determinados discursos, ou seja, a regularidade de certos conhecimentos. Daí por que Foucault (2012), numa posição arqueológica, sugeriu que a unidade de um discurso fosse baseada tanto na permanência e na singularidade de um objeto, quanto no espaço nos quais vários objetos emergem e são continuamente transformados.

\section{MICHEL FOUCAULT E O DISCURSO DENTRO DE UM CAMPO DE PODER EM GENEALOGIA DO PODER 12}

O projeto Genealógico em Foucault aparece em seu pensamento a partir da década de 1970, principalmente, com as obras Vigiar e Punir, História da Sexualidade I: A Vontade do Saber, além das conferências e palestras proferidas reunidas em vários livros. Já na Aula inaugural no Collège de France, pronunciada em 2 de dezembro de 1970, que deu origem ao Livro A Ordem do Discurso, encontramos marcas claras desse seu novo projeto intelectual, ao tecer comentários sobre o discurso e a sua análise dentro de um sistema de controle ou de um campo de poder:

Quanto ao aspecto genealógico, este concerne à formação efetiva dos discursos, quer no interior dos limites do controle, quer no exterior, quer, a maior parte das vezes, de um lado e de outro da delimitação. [...] A formação regular do discurso pode integrar, sob certas condições e até certo ponto, os procedimentos do controle (é o que se passa, por exemplo, quando uma disciplina toma forma e estatuto de discurso científico); e, inversamente, as figuras do controle podem tomar corpo no interior de uma formação discursiva (assim, a crítica literária como discurso constitutivo do autor): de sorte que toda tarefa crítica, pondo em questão as instâncias do controle, deve analisar ao mesmo tempo as regularidades discursivas através das quais elas se formam; e toda descrição genealógica deve levar em conta os limites que interferem nas formações reais (FOUCAULT, 2011, p. 65).

Essas palavras mostram o novo direcionamento do pensamento foucaultiano, isto é, um direcionamento dentro da perspectiva não mais Arqueológica e sim numa visão mais Genealógica13, na medida em que procurava focar sua reflexão de preferência nas questões do poder ou das estratégias de controle dos discursos.

No projeto Arqueológico, Foucault estudou as teorias das ciências humanas no âmbito do sistema autônomo do discurso, tendo transformado a história das ciências inteligíveis ou compreensíveis em termos de suas regras discursivas. Ou seja, das regras que regulavam os seus discursos. No projeto genealógico, pode-se colocar o pensamento foucaultiano dentro de uma perspectiva do discurso e os seus desempenhos dentro de um sistema de relações de poder. Na

\footnotetext{
${ }^{12}$ As concepções aqui apresentadas com relação ao pensamento genealógico de Foucault estão centradas nas reflexões feitas com base no livro História da Sexualidade 1: A vontade do Saber (2005) e Michel Foucault: Estratégia, Poder-Saber (2006).

13 É importante que fique claro que não há um abandono total do pensamento arqueológico em Foucault. Ao passar a ter uma perspectiva mais genealógica, Foucault busca uma relação entre a Arqueologia e a Genealogia, dentro de uma perspectiva de complementação de projetos intelectuais. Com isso, as análises arqueológicas e genealógicas são complementares (RABINOW; DREYFUS, 2010).
} 
Genealogia, Foucault estava preocupado com as questões atinentes, principalmente, à utilização e à representação dos discursos dentro de um campo de forças ${ }^{14}$.

Sem dúvida, Foucault apresentou um método de diagnosticar e compreender o significado das práticas sociais a partir das relações de poder. 0 genealogista é aquele que diagnostica e interpreta as relações de poder estabelecidas nas várias esferas da sociedade, ou seja, nos seus vários tempos e espaços. Uma das principais ideias que perpassam o pensamento foucaultiano refere-se ao jogo de forças em qualquer situação histórica. A preocupação do genealogista é com o surgimento do campo de forças ou de poder em que os discursos aparecem e no qual os sujeitos estão imersos ${ }^{15}$.

A partir da leitura de Foucault (2005), o autor deixa claro que sua preocupação não é com a elaboração de uma teoria sobre o poder, mas a apresentação de uma "analítica do poder". Para Foucault (2005), o "Poder" não existe, o que existe são relações de poder que emergem em determinados espaços e em tempos dados. 0 "Poder" no pensamento foucaultiano é uma correlação de forças, um "jogo de lutas e afrontamentos", onipresente em todas as esferas da sociedade. Ou seja, o poder se reproduz em todas as relações, ganhado corpo em todas as instituições, presente em toda parte. Nesta perspectiva,

[...] o poder, primeiro, como a multiplicidade de correlações de força imanentes ao domínio onde se exercem e constitutivas de sua organização; o jogo que, através de lutas e afrontamentos incessantes as transforma, reforça, inverte; [...] Onipresença do poder: não porque tenha privilégio de agrupar tudo sob a invencível unidade, mas porque se produz a cada instante, em todos os pontos, ou melhor, em toda relação entre um ponto e outro. 0 poder está em toda a parte; não porque engloba tudo e sim porque provém de todos os lugares (FOUCAULT, 2005, p. 88).

Outro ponto que aparece bem evidente neste pensamento foucaultiano diz respeito à existência de uma grande rede de micro-poderes articulados em todas as esferas da sociedade ${ }^{16}$. Não existe um

\footnotetext{
14 Rabinow; Dreyfus (2010) deixam muito claro essa mudança de pensamento em Foucault ao afirmar que seu posicionamento como genealógico ficou centrado em questões mais da prática do que da teoria, posicionamento diferente do Foucault arqueólogo. Assim: Nos trabalhos posteriores de Foucault (posteriores à Arqueologia), em todos os níveis, a prática é considerada mais fundamental do que a teoria. [...] a inteligibilidade das ciências do homem não deve ser buscada em algum sistema de regras de formação, nem no horizonte do significado compartilhado pelos autores. Ou melhor dizendo, Foucault, a partir de então, achava que as ciências humanas eram inteligíveis como parte de um conjunto maior de práticas organizadas e organizadoras, em cuja expansão as ciências humanas desempenham papel crucial. [...] 0 investigador não é mais o espectador desligado dos momentos discursivos mudos. [...] Foucault introduz a genealogia como um método de diagnosticar e compreender o significado das práticas sociais a partir do seu próprio interior (RABINOW; DREYFUS, 2010, p. 137).

15 Como se pode perceber, em genealogia, o pensamento foucaultiano está centrado não no sujeito ou no seu papel dentro do campo de forças do poder, mas nos discursos desses sujeitos emergindo no campo das forças discursivas (RABINOW; DREYFUS, 2010). Igualmente, em A Arqueologia do Saber, o sujeito também é assujeitado, mas é um sujeito que está imerso em um campo de forças que determinam a sua posição dentro do campo dos discursos.

${ }^{16}$ Foucault (2005) deixou claro que o poder ou as relações de poder que ele analisou não se acha restrita ao Estado, como centro do poder, ou a algum centro de formação. Para o referido autor, o Estado é só mais uma instituição, não há na sociedade um único sistema de dominação onde o poder se concentra: Dizendo poder, não quero significar "o Poder", como um conjunto de instituições e aparelhos garantidores da sujeição dos cidadãos em um Estado determinado. Também não entendo poder como modo de sujeição que, por oposição à violência, tenha a forma da regra. Enfim, não o entendo como um sistema geral de dominação, exercida por um elemento ou grupo sobre outro e cujos efeitos, por derivações sucessivas, atravessam o corpo social inteiro" (FOUCAULT, 2005, p. 88).
} 
poder único, no Estado ou outra grande instituição. Ao contrário, o que existe é uma rede de vários poderes que se estabelecem em vários espaços da estrutura social.

Com isso, uma das principais ideias de Foucault (2005) reside no fato de que não existe um único centro, mas um campo de forças, onde cada poder busca estabelecer uma série de mecanismos. Portanto, o poder não tem um centro único ou uma instituição que a domine para si, como também o poder não vem de cima para baixo ${ }^{17}$. As relações de poder, como nos apresentava Foucault (2005), "atravessam todo o corpo social", ligando-se a todas as esferas de dominação e de resistências possíveis. Assim, afirmou Foucault (2005):

Da mesma forma que a rede das relações de poder acaba formando um tecido espesso que atravessa os aparelhos e as instituições, sem se localizar exatamente neles, também a pulverização dos pontos de resistência atravessa as estratificações sociais e as unidades individuais. [...] É exatamente nesse campo das relações de força que se deve analisar os mecanismo de poder (FOUCAULT, 2005, p. 92).

Como se pode perceber, a analítica do poder em Foucault (2005) está centrada na busca de interpretação e análise dos mecanismos de poder e nas estratégias de afirmação de determinadas relações de poder. Seu grande projeto teórico em Genealogia foi, portanto, buscar entender como se dá a emergência e o estabelecimento de relações de poder (RABINOW; DREYFUS, 2010). Rabinow (2010), ao fazer uma leitura e interpretação do pensamento foucaultiano, confirma a concepção do poder enquanto existência ou materialidade, uma vez que não existem dominantes e dominados nesse campo de forças; mas um conjunto de "micropráticas sociais" que se estabelecem nas relações cotidianas, de caráter "desigual e móvel" em vários espaços e tempos. Daí por que ele reafirma a ideia de Foucault de que o poder é um conjunto de relações desiguais, móveis e assimétricas. Diz ele:

[...] as relações de poder são "desiguais e móveis". o poder não é uma mercadoria, uma posição, uma recompensa ou uma trama; é uma operação de tecnologias políticas através do corpo social. [...] Para compreender o poder e sua materialidade, seu funcionamento diário, devemos nos remeter ao nível das micropráticas, das tecnologias políticas em que nossas práticas se formam (RABINOW; DREYFUS, 2010, p. 243).

Na verdade, o que Foucault procurou fazer dentro da perspectiva da Genealogia foi mostrar que o Genealogista é, portanto, aquele que diagnostica e interpreta as relações de poder existentes na sociedade. Fica claro que para Foucault o poder não se concentra em um único lugar ou em uma única instituição, o poder é aquele que faz parte do corpo social, ele está presente em todas as suas esferas, em todas as práticas sociais, constituindo para isso um campo de acontecimento ou um campo de correlações de força.

\footnotetext{
17 Segundo nos mostrou Foucault (2006), as relações de poder se estabelecem em todas as relações, nas várias "microlutas" diárias. Foucault (2006) deixou claro que: Na sociedade, há milhares e milhares de relações de poder e, por conseguinte, relações de forças de pequenos enfrentamentos, microlutas, de algum modo. Se é verdade que essas pequenas relações de poder são com frequência comandadas, induzidas do alto pelos grandes poderes de Estado ou pelas grandes dominações de classe, é preciso ainda dizer que, em sentido inverso, uma dominação de classe ou uma estrutura de Estado só podem funcionar se houver, na base, as pequenas relações de poder (FOUCAULT, 2006, p. 231).
} 
Dentro dessa concepção, Foucault (2005) mostra claramente que o problema do discurso ou da análise do discurso, na visão genealógica, está centrado na questão do discurso emergindo nas relações de poder. Ou seja, a questão refere-se à natureza discursiva do poder, ficando evidente que o discurso acha-se intrinsecamente vinculado ao poder.

Em História da Sexualidade 1: A Vontade de Saber, Foucault (2005) deixa claro que todo o poder institui um discurso da verdade, do saber, referindo-se, de forma específica neste livro, ao discurso sobre o sexo. Diz ele:

Quanto ao sexo e aos discursos da verdade que dele se ocuparam, a questão a resolver não será, portanto: dada a estrutura estatal, como e porque "o" poder precisa instituir um saber sobre o sexo? Também não deverá ser: a que dominação global serviu, desde o século até a preocupação em produzir discursos verdadeiros sobre o sexo? Nem tampouco: que lei presidiu, ao mesmo tempo, à regularidade do comportamento sexual e à conformidade do que se dizia sobre ele? Ao contrário: em tal tipo de discurso sobre o sexo em tal forma de extorsão de verdade que aparece historicamente e em lugares determinados, quais são as relações de poder mais imediatas, mais locais, que estão em jogo? Como tornam possíveis essas espécies de discursos e, inversamente, como esses discursos lhes servem de suporte? (FOUCAULT, 2005, p. 92).

Sem dúvida, a importância dessa afirmação e o que fica evidente nas investigações de Foucault é que o domínio sobre o discurso da sexualidade se estabelece pelas relações de poder ${ }^{18}$. A sexualidade se constitui e se estabelece como um domínio do saber das relações de poder. Assim, afirma Foucault (2005): "Se a sexualidade se constitui como domínio a conhecer, foi a partir de relações de poder que a instituíram como objeto possível" (FOUCAULT, 2005, p. 93).

Ao mesmo tempo, Foucault (2005) mostra que todo discurso se articula com relações de poder e saber. Para o Genealogista, o discurso não é uma simples "projeção desses mecanismos de poder", mas é uma articulação de poder e saber. Com isso, não existe um discurso do poder e outro sem poder. Os discursos estão dentro do poder e do seu campo de forças. Com isso, o discurso produz, reforça, alimenta relações de poder.

\section{CONCLUSÃO}

Enfim, será que se deve "fragmentar" o Foucault da Arqueologia do Saber e o Foucault da Genealogia do Poder? Ou entendê-los no âmbito de uma obra densa, talvez complementando-se como uma totalidade complexa?

\footnotetext{
${ }^{18}$ Segundo nos mostra Foucault (2011), em toda a sociedade o discurso é controlado, selecionado, organizado e redistribuído dentro do campo das relações de poder. Sabe-se a partir de Foucault (2011), que o discurso se apresenta como um sistema de exclusão, a partir de procedimentos de controle e delimitação, o qual denominou de interdição: Em uma sociedade como a nossa, conhecemos, é certo, procedimentos de exclusão. 0 mais evidente, o mais familiar também, é a interdição. Sabe-se bem que não se tem o direito de dizer tudo, que não se pode falar de tudo em qualquer circunstância, que qualquer um, enfim, não pode falar de qualquer coisa (FOUCAULT, 2011, p. 9).
} 
Suspeitamos que com a passagem do projeto arqueológico ao projeto genealógico há, no pensamento foucaultiano, uma mudança de ênfase em termos da forma de compreensão do discurso e de suas dimensões. Porém, que não fragmenta a sua obra e seu pensamento. Não enfatizamos se há em Foucault uma posição mais estruturalista numa primeira fase de seu pensamento ou uma posição pósestruturalista na sua segunda fase, mas observamos a mudança de ênfase na análise do discurso em ambas as fases de seu projeto intelectual.

Voltemos ao questionamento inicial do texto: Quais as implicações teórico-metodológicas do estudo do discurso a partir das abordagens da Arqueologia e da Genealogia em Foucault?

Em A Arqueologia do Saber, Foucault (2012) estava mais preocupado com as questões que envolviam as formações discursivas de certas disciplinas humanas, ou seja, o conjunto de enunciados sobre um determinado conhecimento, dentro de um sistema de discursos guiados por regras que permitem a existência dos enunciados ditos. Ele tentou formar uma história das ciências humanas através das regras que regulavam e conduziam os sujeitos no ato e na formação de seus discursos: "A Arqueologia busca definir não os pensamentos, as representações, as imagens os temas, as obsessões que se ocultam ou se manifestam nos discursos, mas os próprios discursos, enquanto práticas que obedecem a regras" (FOUCAULT, 2012, p. 163).

Na visão arqueológica, as práticas discursivas, as quais consequentemente levam às práticas sociais, eram vistas como construídas e adequadas a partir das regras dos discursos reinantes. 0 papel do Arqueólogo consistiria então em descrever as regras que comandam as práticas discursivas dentro do quadro das ciências e instituições sociais, numa tentativa de chegar aos discursos e às formações de seus objetos nas suas especificidades. Com isso, nessa perspectiva, a questão arqueológica não vê o sujeito como o "dono" de um determinado discurso, o sujeito aí é "assujeitado", mas a preocupação do arqueólogo deve ser com a "descrição sistemática" do discurso em seu acontecimento.

No projeto Genealógico, o discurso passa a ser implícito nas relações de poder, na "analítica do poder". Percebe-se uma passagem ou mudança de análise dos enunciados dentro de um quadro das formações discursivas, caracterizadas anteriormente em termos de disciplinas particulares, passando agora para uma perspectiva mais genealógica a enfatizar discursos mais genéricos, tais como entrevista, exame e confissão, entre outros.

Uma das preocupações centrais inerente a esta nova fase da sua obra referia-se à natureza discursiva do poder. Isto na medida em que o genealogista traduzia-se naquele que passa a analisar as relações na sociedade através das relações de poder, saber e do corpo. 0 poder passa a ser o elemento que conduzia à explicação foucaultiana nesta fase, fazendo com que o discurso passasse a ser secundário ao poder. Isso acontecia uma vez que o poder, para se estabelecer, utiliza-se de mecanismos ou estratégias de discursos para estar presente em vários campos no corpo social. Daí o surgimento de discursos da loucura, doença, morte, sexualidade, crime, etc. 
Mesmo em Genealogia, compreende-se que o sujeito também é "assujeitado", pois a preocupação não seria mais com o sujeito em si e os seus discursos, mas com os discursos desses sujeitos emergindo no campo de forças sociais ou de poder. A preocupação do Genealogista constitui, assim, um novo nível de análise do discurso como fruto suscitado no campo de forças onde vai se articular a relações de poder.

Com isso, podemos afirmar que há de fato implicações teórico-metodológicas ao tomar Foucault como referencial em uma pesquisa, uma vez que o discurso ou a análise do discurso, dentro da visão de Michael Foucault, vai modificar-se a partir de suas fases ou projetos intelectuais. Porém, essa implicação não significa fragmentação de Michel Foucault.

\section{REFERÊNCIAS}

DREYFUS, Hubert L.; RABINOW, Paul. Michel Foucault: uma trajetória filosófica: para além do estruturalismo e da hermenêutica. $2^{\circ}$ ed., rev., Rio de Janeiro, Editora Fourense Universitária, 2012.

FOUCAULT, Michel. A ordem do discurso. 21ำ edição, Edições Loyola, São Paulo, 2011.

. A Arqueologia do Saber. $8^{\circ}$ edição, Rio de Janeiro, Editora Fourense Universitária, 2012. . História da sexualidade 1: A vontade de saber, Rio de Janeiro, Editora Graal, 2005. . Michel Foucault: Estratégia, Poder-Saber, $2^{\circ}$ edição, Rio de Janeiro, Fourense Universitária, 2006. 